\title{
Pharmacokinetics of loxoprofen in a self- administered overdose in a Japanese patient admitted to hospital
}

Koichiro Adachi ${ }^{1,2,3}$, Yuki Sugitani ${ }^{2}$, Ryo Unita ${ }^{2}$, Kosuke Yoshida², Satoru Beppu², Mariko Terashima², Masaya Fujii ${ }^{2}$, Makiko Shimizu ${ }^{1}$ and Hiroshi Yamazaki ${ }^{*}$ (D)

\begin{abstract}
Background: Loxoprofen is a propionic acid derivative and is the most widely prescribed non-steroidal antiinflammatory drug in Japan. Loxoprofen is generally considered to be relatively nontoxic.

Case presentation: A 33-year-old man (body weight, $55 \mathrm{~kg}$ ) who intentionally took an overdose of 100 tablets of loxoprofen $(6000 \mathrm{mg})$ as a suicide attempt was emergently admitted to Kyoto Medical Center. On arrival, the patient was suffering disorders of consciousness. His plasma concentrations of loxoprofen and its reduced trans-alcohol metabolite were 52 and $24 \mu \mathrm{g} / \mathrm{mL}, 3.7$ and $2.3 \mu \mathrm{g} / \mathrm{mL}, 0.81$ and $0.54 \mu \mathrm{g} / \mathrm{mL}$, and 0.015 and $0.011 \mu \mathrm{g} / \mathrm{mL}$, respectively, at 4, 26, 50, and $121 \mathrm{~h}$ after the oral overdose. The observed apparent terminal elimination half-life of loxoprofen during days 1 and 2 of hospitalization was in the range $6-12 \mathrm{~h}$, which is several times longer than the reported normal value. This finding implied nonlinearity of loxoprofen pharmacokinetics over the current 100-fold dose range, which could affect the accuracy of values simulated by a simplified physiologically based pharmacokinetic (PBPK) model founded on data from a normal dose of $60 \mathrm{mg}$. The reasons for the delayed eliminations from plasma of loxoprofen and its trans-alcohol metabolite in this case are uncertain, but slight renal impairment (low eGFR values) developed on the second and third hospital days and could be a causal factor.

Conclusions: Because the patient's level of consciousness had gradually improved, he was discharged on the fourth day of hospitalization. The virtual plasma exposures of loxoprofen and its reduced trans-alcohol metabolite estimated using the current simplified PBPK model were lower than the measured values in the overdose case. The present results based on drug monitoring data and pharmacokinetic predictions could serve as a useful guide in cases of loxoprofen overdose.
\end{abstract}

Keywords: Pharmacokinetic modeling, Overdose, Absorption, Elimination

\footnotetext{
* Correspondence: hyamazak@ac.shoyaku.ac.jp

'Laboratory of Drug Metabolism and Pharmacokinetics, Showa

Pharmaceutical University, 3-3165 Higashi-tamagawa Gakuen, Machida, Tokyo 194-8543, Japan

Full list of author information is available at the end of the article
}

(C) The Author(s). 2021 Open Access This article is licensed under a Creative Commons Attribution 4.0 International License, which permits use, sharing, adaptation, distribution and reproduction in any medium or format, as long as you give appropriate credit to the original author(s) and the source, provide a link to the Creative Commons licence, and indicate if changes were made. The images or other third party material in this article are included in the article's Creative Commons licence, unless indicated otherwise in a credit line to the material. If material is not included in the article's Creative Commons licence and your intended use is not permitted by statutory regulation or exceeds the permitted use, you will need to obtain permission directly from the copyright holder. To view a copy of this licence, visit http://creativecommons.org/licenses/by/4.0/. The Creative Commons Public Domain Dedication waiver (http://creativecommons.org/publicdomain/zero/1.0/) applies to the data made available in this article, unless otherwise stated in a credit line to the data. 


\section{Background}

Loxoprofen, a propionic acid derivative, acts as a cyclooxygenase inhibitor and has been in clinical use since 1986 in the world $[1,2]$. Loxoprofen is currently the most prescribed non-steroidal anti-inflammatory drug (NSAID) in Japan (30\% of 2,000,000 patients using NSAIDs in 2017 [3]). Loxoprofen is a prodrug that is reduced to its active metabolite, the trans-alcohol form, by carbonyl reductase enzymes in the liver [4]. Although loxoprofen is often considered to be relatively nontoxic, one case report suggested prolonged intrahepatic cholestasis in a woman after normal use for 5 days [5]. Also, a man who died as a result of an anaphylactic reaction had a postmortem blood loxoprofen concentration of $1.2 \mu \mathrm{g} / \mathrm{mL}$, which is within the therapeutic range [6]. The monitoring of plasma concentrations of loxoprofen may be considered in clinical or emergency situations.

The drug monitoring of steady-state plasma concentrations of individual patients in the clinical setting can be supported by pharmacokinetic models and simulations. Full physiologically based pharmacokinetic (PBPK) models [7] can predict drug monitoring results in patients [8-10]. However, we have developed simplified PBPK models [11] and have applied these models to cases of edoxaban overdose [12] and a combined overdose of duloxetine with other antipsychotic drugs [13]. The practical application of such PBPK models is suggested for paramedical staff in emergency clinical practice $[12,13]$.

\section{Case presentation}

Here, we describe the case of a 33-year-old man (body weight, $55 \mathrm{~kg}$ ) who intentionally took an overdose of 100 tablets $(6000 \mathrm{mg}$ ) of loxoprofen (usual clinical dose in the range $60-180 \mathrm{mg} /$ day $[1,2])$. On arrival at Kyoto Medical Center, with empty heat seals for loxoprofen, the patient was suffering disorders of consciousness. His awareness level was assessed, and the Glasgow Coma Scale score was eye 1, verbal 1, and motor 1 (E1V1M1). Contralateral light reflexes were bilateral $2 / 2(-/-)$, the blood pressure was $150 / 90 \mathrm{mmHg}$, the heart rate was $106 \mathrm{bpm}$, the respiratory rate was $18 / \mathrm{min}$, and the body temperature was $36.7^{\circ} \mathrm{C}$. No rigidity of the arm and no snore-like breathing were noted in an arm drop test. The following tests all gave negative results: drug intoxication (Triage DOA, Sysmex, Kobe, Japan), head computed tomography, magnetic resonance imaging, spinal fluids, and simple electroencephalography. After the patient's level of consciousness had gradually improved, subsequent questioning revealed that he had taken a high dose of loxoprofen but had not consumed any alcohol. The family of the patient was also interviewed regarding the circumstance of overdoses. No history of asthma, hepatic dysfunction, impaired renal function, or autoimmune disease or a family history of autoimmune disease was noted. The clinical laboratory results for the current patient are shown in Table 1 . The patient developed slight renal impairment (low eGFR values) on the second and third days of hospitalization, but was discharged on the fourth day of hospitalization.

We report herein the measured plasma concentrations of loxoprofen and its reduced trans-alcohol metabolite during 3 days of hospitalization and the PBPK-modeled concentration profiles of loxoprofen self-administered after a single oral overdose (Fig. 1B). The patient gave written informed consent to take part in this study and for its publication. The Ethics Committee of Kyoto Medical Center approved this study (18-018). Frozen plasma samples collected from the patient were pharmacokinetically analyzed. After samples were deproteinized with four volumes of acetonitrile, the plasma concentrations of loxoprofen and its reduced trans-alcohol metabolite were quantified by liquid chromatography using a gradient elution program followed by tandem mass spectrometry [13] according to the previously reported methods [4] with slight modifications. An API4000 tandem mass analyzer (AB Sciex, Framingham, MA, USA) was used in electrospray negative ionization mode and was directly coupled to a Shimadzu LC-20 AD system equipped with an octadecylsilane $\left(\mathrm{C}_{18}\right)$ column (XBridge, $3.5 \mu \mathrm{m}, 2.1$ $\mathrm{mm} \times 150 \mathrm{~mm}$, Waters, Milford, MA, USA). The LC conditions were as follows: solvent A was $0.1 \%$ formic acid in water, and solvent $\mathrm{B}$ was $0.1 \%$ formic acid in acetonitrile. The following gradient program was used with a flow rate of $0.25 \mathrm{~mL} / \mathrm{min}$ : $0.0-0.5 \mathrm{~min}$, hold at $10 \% \mathrm{~B} ; 0.5-21 \mathrm{~min}$, linear gradient from $10 \% \mathrm{~B}$ to $50 \% \mathrm{~B}$ (v/v); 21-22 min, linear gradient from $50 \%$ B to $95 \%$ B (v/v); 22-25 min, hold at 95\% B; and 25.1-30 min, hold at $10 \% \mathrm{~B}$. The temperature of the column was maintained at $40{ }^{\circ} \mathrm{C}$. Prepared samples $(2.0 \mu \mathrm{L})$ were injected using an auto-sampler. Loxoprofen and its reduced trans-alcohol metabolite were quantified using $\mathrm{m} / \mathrm{z}$ $245 \rightarrow 83$ and $m / z \quad 247 \rightarrow 191$ transitions, respectively. Loxoprofen- $d_{3}$ and trans-loxoprofen- $d_{3}$ alcohol were used as internal standards using $\mathrm{m} / \mathrm{z} 248 \rightarrow 83$ and $\mathrm{m} / \mathrm{z}$ $250 \rightarrow 194$ transitions, respectively. Under the present conditions, the plasma levels of loxoprofen and its

Table 1 Clinical laboratory results for a patient who took a single oral overdose of $6000 \mathrm{mg}$ loxoprofen

\begin{tabular}{lllll}
\hline & Day 1 & Day 2 & Day 3 & Day 6 \\
\hline Aspartate aminotransferase $(\mathrm{U} / \mathrm{L})$ & 45 & 39 & 46 & 32 \\
Alanine aminotransferase $(\mathrm{U} / \mathrm{L})$ & 30 & 27 & 29 & 28 \\
eGFR $(\mathrm{mL} / \mathrm{min} / 1.73 \mathrm{~m} 2)$ & 77.0 & 62.8 & 68.9 & 90.8 \\
Serum creatinine $(\mathrm{mg} / \mathrm{dL})$ & 0.93 & 1.12 & 1.03 & 0.80 \\
Creatinine clearance $(\mathrm{mL} / \mathrm{min})$ & 87.9 & 73.0 & 79.4 & 102.0 \\
\hline
\end{tabular}



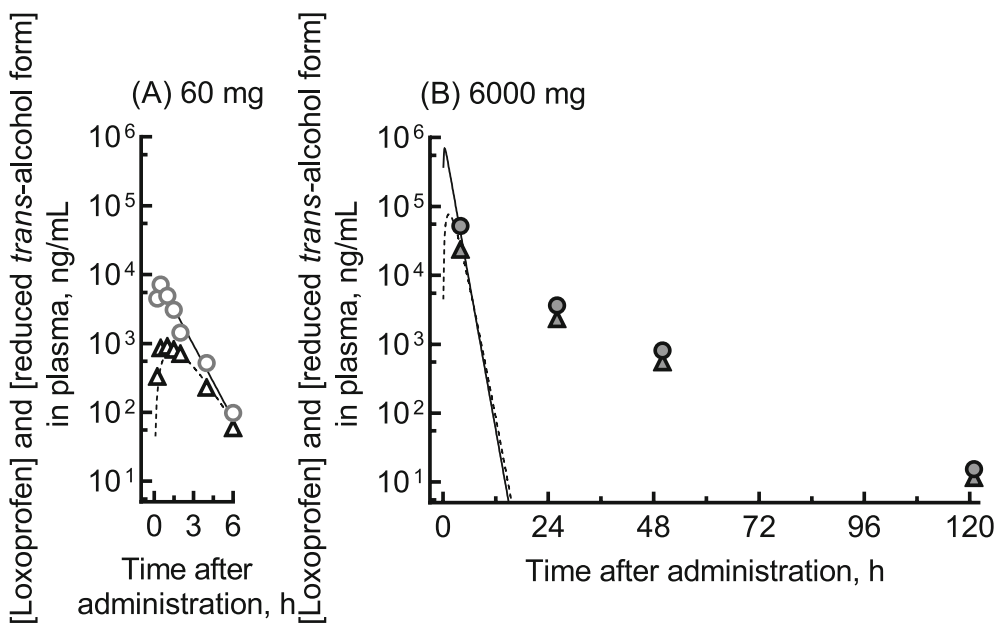

Fig. 1 Measured (plots) and estimated (lines) plasma concentrations of loxoprofen and its reduced trans-alcohol metabolite: measured values were from the literature (A) and from the patient who took a single oral overdose (B). Plasma concentrations of loxoprofen (circles) and its reduced metabolite (triangles) were taken from the literature for 24 volunteers who were administered a therapeutic dose of $60 \mathrm{mg}[4,14]$ (A). Plasma concentrations of loxoprofen are also shown for the patient who took a single oral overdose of $6000 \mathrm{mg}$ (B). The PBPK-modeled plasma concentration curves for loxoprofen (solid lines) and its reduced trans-alcohol metabolite (broken lines) after virtual administration of loxoprofen are also shown

reduced trans-alcohol metabolite were measurable at $\geq 10 \mathrm{ng} / \mathrm{mL}$ and detectable at $\geq 1.0 \mathrm{ng} / \mathrm{mL}$. Authentic loxoprofen and its reduced trans-alcohol form were purchased from Fujifilm Wako Pure Chemicals, Osaka, Japan, and loxoprofen- $d_{3}$ and the trans-alcohol form of loxoprofen- $d_{3}$ were purchased from Toronto Research Chemicals, North York, ON, Canada. The measured plasma concentrations of loxoprofen selfadministered in a single oral overdose are shown in Fig. 1B. The plasma concentrations of loxoprofen and its reduced trans-alcohol form in the current patient were 52 and $24 \mu \mathrm{g} / \mathrm{mL}, 3.7$ and $2.3 \mu \mathrm{g} / \mathrm{mL}, 0.81$ and $0.54 \mu \mathrm{g} / \mathrm{mL}$, and 0.015 and $0.011 \mu \mathrm{g} / \mathrm{mL}$ at $4,26,50$, and $121 \mathrm{~h}$, respectively, after an oral overdose of $6000 \mathrm{mg}$.

We also report the results of in silico pharmacokinetic modeling of plasma concentrations. Based on the reported human blood concentrations after 24 healthy volunteers were orally administered a normal therapeutic dose $[4,14]$ (shown in Fig. 1A), a simple loxoprofen PBPK model consisting of gut, liver, kidney, and central and peripheral compartments was set up as described previously $[12,13,15]$. The initial values for the fraction absorbed $\times$ intestinal availability $\left(F_{\mathrm{a}} \cdot F_{\mathrm{g}}\right)$ and hepatic clearance $\left(C L_{\mathrm{h}}\right)$ were estimated from the elimination constants in empirical one-compartment models. As input parameters for the PBPK model, the absorption rate constant $\left(k_{\mathrm{a}}\right)$, volume of the systemic circulation $\left(V_{1}\right)$, and hepatic intrinsic clearance $\left(C L_{\mathrm{h}, \text { int }}\right)$ values, with standard deviations, were determined by fitting using nonlinear regression analyses; these final parameters are shown in Table 2. The resulting system of differential equations was solved to obtain the concentrations of the substrate and its metabolite (indicated with subscript $m$ ) for the overdosed patient in this study:

$$
\begin{aligned}
\begin{aligned}
& \frac{d X_{g}}{d t}=- k_{a} \cdot X_{g} \text { where at } t=0, X_{g}(0)=F \mathrm{a} \cdot F \mathrm{~g} \cdot \text { dose } \\
& V_{h} \frac{d C_{h}}{d t}= k_{a} \cdot X_{g}-\frac{Q_{h} \cdot C_{h} \cdot R_{b}}{K_{p, h}}-C L_{h, i n t} \cdot \frac{C_{h}}{K_{p, h}} \cdot f_{u, p} \\
&+Q_{h} \cdot C_{b} \\
& V_{1} \frac{d C_{b}}{d t}=-\left(Q_{h}+Q_{r}\right) \cdot C_{b}+\frac{Q_{h} \cdot C_{h} \cdot R_{b}}{K_{p, h}} \\
&+ \frac{Q_{r} \cdot C_{r} \cdot R_{b}}{K_{p, r}} \\
& V_{r} \frac{d C_{r}}{d t}=Q_{r} \cdot C_{b}-\frac{Q_{r} \cdot C_{r} \cdot R_{b}}{K_{p, r}}-C L_{r} \cdot \frac{C_{r}}{K_{p, r}} \cdot f_{u, p} \\
& V_{h, m} \frac{d C_{h, m}}{d t}= Q_{h} \cdot C_{b, m}-\frac{Q_{h} \cdot C_{h, m} \cdot R_{b, m}}{K_{p, h, m}}+C L_{h, i n t} \\
& \cdot \frac{C_{h}}{K_{p, h}} \cdot f_{u, p}-C L_{h, i n t, m} \cdot \frac{C_{h, m}}{K_{p, h, m}} \cdot f_{u, p, m} \\
& V_{1, m} \frac{d C_{b, m}}{d t}=-\left(Q_{h}+Q_{r}\right) \cdot C_{b, m}+\frac{Q_{h} \cdot C_{h, m} \cdot R_{b, m}}{K_{p, h, m}} \\
&+\frac{Q_{r} \cdot C_{r, m} \cdot R_{b, m}}{K_{p, r, m}} \\
& V_{r, m} \frac{d C_{r, m}}{d t}= Q_{r} \cdot C_{b, m}-\frac{Q_{r} \cdot C_{r, m} \cdot R_{b, m}}{K_{p, r, m}}-C L_{r, m} \\
& \cdot \frac{C_{r, m}}{K_{p, r, m}} \cdot f_{u, p, m}
\end{aligned}
\end{aligned}
$$

where $X_{\mathrm{g}}, V_{\mathrm{h}}, V_{\mathrm{r}}, C_{\mathrm{h}}, C_{\mathrm{r}}$, and $C_{\mathrm{b}}$, respectively, are the amounts of compound in the gut compartment; the liver 
Table 2 Physiological, experimental, and final calculated parameters for loxoprofen PBPK model established in this study

\begin{tabular}{cc}
\hline Parameter $\quad$ Loxoprofen & $\begin{array}{l}\text { Reduced trans- } \\
\text { alcohol metabolite } \\
\text { of loxoprofen }\end{array}$ \\
\hline
\end{tabular}

\begin{tabular}{|c|c|c|}
\hline \multicolumn{3}{|l|}{ Model input parameters } \\
\hline Molecular weight & 246 & 248 \\
\hline $\begin{array}{l}\text { Octanol-water partition } \\
\text { coefficient }\end{array}$ & 1.97 & 2.23 \\
\hline Plasma unbound fraction & 0.0681 & 0.0559 \\
\hline Blood-plasma concentration ratio & 0.799 & 0.782 \\
\hline Liver-plasma concentration ratio & 1.15 & 1.49 \\
\hline $\begin{array}{l}\text { Fraction absorbed } \times \text { intestinal } \\
\text { availability }\end{array}$ & 1 & - \\
\hline Absorption rate constant, 1/h & $6.17 \pm 0.27^{\mathrm{a}}$ & - \\
\hline Volume of systemic circulation, $\mathrm{L}$ & $4.67 \pm 0.17^{\mathrm{a}}$ & $11.4 \pm 0.3^{a}$ \\
\hline Hepatic intrinsic clearance, L/h & $76.3 \pm 0.3^{\mathrm{a}}$ & $215 \pm 1^{\mathrm{a}}$ \\
\hline Hepatic clearance, L/h & 4.93 & 10.7 \\
\hline Renal clearance, L/h & 0.10 & 1.1 \\
\hline \multicolumn{3}{|l|}{ Estimated values ${ }^{c}$} \\
\hline $\mathrm{C}_{\max }$ in plasma, $\mathrm{ng} / \mathrm{mL}$ & $6940(0.97)^{b}$ & $770(0.86)^{b}$ \\
\hline AUC in plasma, $\mathrm{ng} \mathrm{h/mL}$ & $11,400(1.1)^{b}$ & $2380(0.90)^{b}$ \\
\hline \multicolumn{3}{|l|}{ Reported levels } \\
\hline $\mathrm{C}_{\max }$ in plasma, $\mathrm{ng} / \mathrm{mL}{ }^{\mathrm{d}}$ & 7160 & 896 \\
\hline AUC in plasma, $\mathrm{ng} \mathrm{h} / \mathrm{mL}^{\mathrm{d}}$ & 10,700 & 2650 \\
\hline Bioavailability ${ }^{d}$ & 1 & - \\
\hline $\begin{array}{l}\text { Urinary excretion of unchanged } \\
\text { drug } d\end{array}$ & 0.02 & - \\
\hline
\end{tabular}

The plasma unbound fraction, octanol-water partition coefficient, blood-toplasma concentration ratio, and liver-to-plasma concentration ratio of loxoprofen and the reduced trans-alcohol metabolite of loxoprofen were estimated using in silico tools [15]

${ }^{a}$ Data are means \pm standard deviations by fitting to observed concentrations

${ }^{b}$ Values in parentheses are ratios to the reported/observed values

c PBPK modeled values for a virtual administration of $60 \mathrm{mg}$ loxoprofen

${ }^{d}$ Taken from the literature $[4,14]$, as shown in Fig. 1A

and kidney volumes; and the hepatic, renal, and blood substrate concentrations. The blood-to-plasma concentration ratio $\left(R_{\mathrm{b}}\right)$ and the liver-to-plasma and kidney-toplasma concentration ratios $\left(K_{\mathrm{p}, \mathrm{h}}\right.$ and $\left.K_{\mathrm{p}, \mathrm{r}}\right)$ of the relevant compounds were estimated from plasma unbound fraction $\left(f_{\mathrm{u}, \mathrm{p}}\right)$ and octanol-water partition coefficient $(\log P)$ values $[11,16,17] . V_{h}$ and $V_{\mathrm{r}}$ are the liver $(1.5 \mathrm{~L})$ and kidney $(0.28 \mathrm{~L})$ volumes, and $Q_{h} / Q_{\mathrm{r}}$ are the blood flow rates of the systemic circulation to the hepatic/renal compartments $(96.6 \mathrm{~L} / \mathrm{h})$ [11].

\section{Discussion and conclusions}

To the best of our knowledge, no case reports are available in the international literature relating to the disturbance of consciousness caused by overdosed loxoprofen. In the present study, we investigated the association between disturbance of consciousness and the expected high blood levels of loxoprofen in the current patient. A single oral $60-\mathrm{mg}$ dose of loxoprofen administered to 24 healthy Korean men resulted in average peak serum concentrations of $4.8 \mu \mathrm{g} / \mathrm{mL}$ at $0.5 \mathrm{~h}$ and $2.4 \mu \mathrm{g} /$ $\mathrm{mL}$ at $0.9 \mathrm{~h}$ for loxoprofen and its reduced trans-alcohol metabolite, respectively [18]. In the current overdose case, the measured plasma concentration levels of loxoprofen were around $50 \mu \mathrm{g} / \mathrm{mL}$. The clinical laboratory results (Table 1) indicate that this plasma level of loxoprofen likely does not cause hepatic impairment, but slight renal impairment was noted. Regarding the absorption phase pharmacokinetics of loxoprofen, it was assumed that loxoprofen at 100 -fold the therapeutic dose was still within the linear range; this assumption was based on the fact that plasma concentrations of loxoprofen and its trans-alcohol metabolite $4 \mathrm{~h}$ after an oral overdose of $6000 \mathrm{mg}$ were consistent with the simulated concentration profiles (Fig. 1B).

In contrast, the elimination phase pharmacokinetics evidently fell outside the linear range. The observed terminal elimination half-life values of 6-12 $\mathrm{h}$ (calculated using two data points) after the 6000-mg dose were several-fold longer than the reported normal values of $1-2 \mathrm{~h}$, thereby implying dose non-linearity for loxoprofen elimination pharmacokinetics over a range of 100 -fold the normal therapeutic dose in the current case (Fig. 1). It was noted in the current case that gastrointestinal symptoms, liver dysfunction, thrombocytopenia, and severe renal failure were not observed. The reasons for the delayed eliminations from plasma of loxoprofen and its trans-alcohol metabolite in this case are uncertain, but slight renal impairment (low eGFR values, Table 1) that developed on the second and third hospital days could be one of the causal factors. It could not be ruled out a possibility that loxoprofen might be biphasically eliminated from the plasma even in the healthy subjects in the range from several hours to $120 \mathrm{~h}$. Although this case report of an overdose of 100 tablets $(6000 \mathrm{mg})$ loxoprofen is considered to be the first to appear in English, the case of a woman in her thirties who took $3600 \mathrm{mg}$ of loxoprofen has been reported in Japanese [19].

In hospitals, a simplified PBPK model-based simulator [20] may replace the need to routinely measure the blood levels of drugs. The present results based on drug monitoring data and pharmacokinetic predictions for the absorption and elimination phases could serve as a promising guide when setting the treatment period in cases of overdoses.

\section{Abbreviations \\ NSAID: non-steroidal anti-inflammatory drug; PBPK: physiologically based pharmacokinetic}

\section{Acknowledgments}

The authors greatly thank Yusuke Kamiya, Norie Murayama, Shiori Hina, Jun Tomizawa, and Wataru Kobari for their technical support, and David Smallbones for copyediting a draft of this article. 


\section{Authors' contributions}

$K A, Y S, R U, K Y, S B$, and MT monitored the patients and carried out the acquisition of patient data. KA, MF, MS, and $\mathrm{HY}$ conceived the pharmacokinetic study and drafted the manuscript. YS, RU, KY, SB, and MT analyzed the patient medical data and helped to draft the manuscript. All authors have read and approved the final manuscript.

\section{Funding}

This work was supported in part by the METI Artificial Intelligence-based Substance Hazard Integrated Prediction System Project, Japan.

\section{Availability of data and materials}

All data generated or analyzed during this study are included in this published article and are also available from the corresponding author on reasonable request.

\section{Declarations}

Ethics approval and consent to participate

This study was approved by the Ethics Committee of Kyoto Medical Center.

\section{Consent for publication}

Informed consent was obtained from the patient.

\section{Competing interests}

The authors declare that they have no competing interests.

\section{Author details}

'Laboratory of Drug Metabolism and Pharmacokinetics, Showa Pharmaceutical University, 3-3165 Higashi-tamagawa Gakuen, Machida, Tokyo 194-8543, Japan. ${ }^{2}$ Kyoto Medical Center, Fushimi-ku, Kyoto 612-8555, Japan.

${ }^{3}$ Present address, Himeji Medical Center, Himeji, Hyogo 670-8520, Japan.

Received: 12 June 2021 Accepted: 18 July 2021

Published online: 07 September 2021

\section{References}

1. Baselt RC. Loxoprofen. Disposition of toxic drugs and chemicals in man. 12th ed. Seal Beach: Biomedical Publications; 2020. p. 1190

2. Greig SL, Garnock-Jones KP. Loxoprofen: a review in pain and inflammation. Clin Drug Invest. 2016;36(9):771-81. https://doi.org/10.1007/s40261-016-044 0-9.

3. Ushida T, Matsui D, Inoue T, Yokoyama M, Takatsuna H, Matsumoto T, et al. Recent prescription status of oral analgesics in Japan in real-world clinical settings: retrospective study using a large-scale prescription database. Expert Opin Pharmacother. 2019;20(16):2041-52. https://doi.org/10.1080/14 656566.2019.1651840.

4. Shrestha R, Cho PJ, Paudel S, Shrestha A, Kang MJ, Jeong TC, et al. Exploring the metabolism of loxoprofen in liver microsomes: the role of cytochrome P450 and UDP-glucuronosyltransferase in its biotransformation. Pharmaceutics. 2018;10(3). https://doi.org/10.3390/pharmaceutics10030112.

5. Ichikawa T, Sato H, Kaira K, Oh IS, Kakizaki S, Sato K, et al. Prolonged intrahepatic cholestasis after exposure to loxoprofen. Clin Ther. 2008;30(12): 2402-6. https://doi.org/10.1016/j.clinthera.2008.12.012.

6. Watanabe T, Sakata M, Shimabukuro R, Sakata K, Tabata N, Azumi J, et al. Loxoprofen - another NSAID associated with acute asthmatic death. J Toxicol Clin Toxicol. 1993;31(2):333-40. https://doi.org/10.3109/155636593 09000400.

7. Jamei M, Marciniak S, Feng K, Barnett A, Tucker G, Rostami-Hodjegan A. The Simcyp population-based ADME simulator. Expert Opin Drug Metab Toxicol. 2009;5(2):211-23. https://doi.org/10.1517/17425250802691074.

8. Ota M, Shimizu M, Kamiya Y, Emoto C, Fukuda T, Yamazaki H. Adult and infant pharmacokinetic profiling of dihydrocodeine using physiologically based pharmacokinetic modeling. Biopharm Drug Dispos. 2019;40(9):350-7. https://doi.org/10.1002/bdd.2209.

9. Notsu Y, Shimizu M, Sasaki T, Nakano A, Ota M, Yoshida S, et al. Simple pharmacokinetic models accounting for drug monitoring results of atomoxetine and its 4-hydroxylated metabolites in Japanese pediatric patients genotyped for cytochrome P450 2D6. Drug Metab Pharmacokinet. 2020;35(2):191-200. https://doi.org/10.1016/j.dmpk.2019.08.005.
10. Emoto C, Shimizu M, Tanaka T, Yamazaki H. Feasibility of physiologically based pharmacokinetic simulations for assessing pediatric patients after accidental drug ingestion: a case study of a 1.4-year-old girl who ingested alprazolam. Drug Metab Pharmacokinet. 2021;39:100394.

11. Kamiya Y, Otsuka S, Miura T, Takaku H, Yamada R, Nakazato M, et al. Plasma and hepatic concentrations of chemicals after virtual oral administrations extrapolated using rat plasma data and simple physiologically based pharmacokinetic models. Chem Res Toxicol. 2019;32(1):211-8. https://doi. org/10.1021/acs.chemrestox.8b00307.

12. Adachi K, Tuchiya J, Beppu S, Nishiyama K, Shimizu M, Yamazaki H. Pharmacokinetics of anticoagulant edoxaban in overdose in a Japanese patient transported to hospital. J Pharm Health Care Sci. 2020;6(1):20. https://doi.org/10.1186/s40780-020-00176-6.

13. Adachi K, Beppu S, Nishiyama K, Shimizu M, Yamazaki H. Pharmacokinetics of duloxetine self-administered in overdose with quetiapine and other antipsychotic drugs in a Japanese patient admitted to hospital. J Pharm Health Care Sci. 2021;7(1):6. https://doi.org/10.1186/s40780-021-00189-9.

14. Naganuma $\mathrm{H}$, Kawahara Y. Enantioselective disposition of loxoprofen in the rat and man. Drug Metab Pharmacokinet. 1990;5(3):447-61. https://doi.org/1 0.2133/dmpk.5.447.

15. Kamiya Y, Otsuka S, Miura T, Yoshizawa M, Nakano A, Iwasaki M, et al. Physiologically based pharmacokinetic models predicting renal and hepatic concentrations of industrial chemicals after virtual oral doses in rats. Chem Res Toxicol. 2020;33(7):1736-51. https://doi.org/10.1021/acs.chemrestox. 0c00009.

16. Uchimura T, Kato M, Saito T, Kinoshita H. Prediction of human blood-toplasma drug concentration ratio. Biopharm Drug Dispos. 2010;31(5-6):28697. https://doi.org/10.1002/bdd.711.

17. Takano R, Murayama N, Horiuchi K, Kitajima M, Kumamoto M, Shono F, et al. Blood concentrations of acrylonitrile in humans after oral administration extrapolated from in vivo rat pharmacokinetics, in vitro human metabolism, and physiologically based pharmacokinetic modeling. Regul Toxicol Pharmacol. 2010;58(2):252-8. https://doi.org/10.1016/jyrtph.2010.06.008.

18. Cho HY, Park CH, Lee YB. Direct and simultaneous analysis of loxoprofen and its diastereometric alcohol metabolites in human serum by on-line column switching liquid chromatography and its application to a pharmacokinetic study. J Chromatogr B Analyt Technol Biomed Life Sci. 2006;835(1-2):27-34. https://doi.org/10.1016/j.jchromb.2006.02.058.

19. Miyoshi H, Sera A, Kato T, Kajiyama S, Kinoshita H. Acute drug overdose with loxoprofen: a case report (in Japanese). JJAAM. 2011;22:772-6.

20. Adachi K, Beppu S, Terashima M, Kobari W, Shimizu M, Yamazaki H. Pharmacokinetic modeling of over-the-counter drug diphenhydramine selfadministered in overdoses in Japanese patients admitted hospital. J Pharm Health Care Sci. 2021. https://doi.org/10.1186/s40780-021-00215-w.

\section{Publisher's Note}

Springer Nature remains neutral with regard to jurisdictional claims in published maps and institutional affiliations.

Ready to submit your research? Choose BMC and benefit from:

- fast, convenient online submission

- thorough peer review by experienced researchers in your field

- rapid publication on acceptance

- support for research data, including large and complex data types

- gold Open Access which fosters wider collaboration and increased citations

- maximum visibility for your research: over $100 \mathrm{M}$ website views per year

At $\mathrm{BMC}$, research is always in progress.

Learn more biomedcentral.com/submissions 